\title{
Factors Affecting Academic Achievement in SW Education
}

\author{
Minjong Cheon, Ook Lee, Changbae Mun, and Hyodong Ha
}

\begin{abstract}
Software industry is becoming the core of technology trend. SW-based changes in education, industry, and social perception are continuously increasing, and thus, computing power is recognized as an essential requirement in higher education. Globally, research on software (SW) education methodology is being actively conducted, and from this point of view, the socio-economic importance of software education is increasing. This study conducted a study on how to identify the educational characteristics and motivations of students. In this study, a method to deal with the motivation for SW education from the perspective of student characteristics was reviewed. For this analysis, the relationship between educational achievement and factors is analyzed, and factors that can affect student achievement are explored. Factors for the methodology are identified and verified with a statistical methodology.
\end{abstract}

Index Terms $-\mathrm{SW}$ education, academic achievement, SW society, learning motivation.

\section{INTRODUCTION}

As the tide of the 4th industrial revolution arrived beyond the information age, major industries get interested in software (SW), it has now become an SW-oriented society. The SW-oriented society represents that even though industries are divided into diverse fields and coexist, SW plays a major role and becomes a representative driving force in major technology fields. Therefore, in an SW-oriented society, SW becomes a center of social change and constructs the competitiveness of individuals and countries [1].

Going with the tide, demand for SW personnel specialized in artificial intelligence (AI) is increasing in various industrial fields [2]. It is crucial for those companies to find professional manpower, where SW is a key business area. SW-related occupations are generally in higher demand for highly skilled manpower than other occupations, making it difficult for companies to secure optimal manpower with requirements at a proper cost [3]. As a matter of fact, the manpower shortage in Korea is not limited to the present. SW technology employees move to other jobs such as general managers in companies [4], and the turnover rate was high on

Manuscript received September 13, 2021; revised October 26, 2021.

M. Cheon and O. Lee are with the Information Systems Department, Hanyang University, Seoul, Korea (e-mail: jmj2316@hanyang.ac.kr, ooklee@hanyang.ac.kr).

C. Mun is with Electrical, Electronic and Communication Engineering Department, Hanyang Cyber University, Seoul, Korea (e-mail: changbae@hycu.ac.kr).

H. Ha is with Software Education Committee, Office of Academic Affairs, Hanyang University, Seoul, Korea (corresponding author; e-mail: special007@hanyang.ac.kr). account of low job satisfaction arising from fairness in compensation [5].

Swimming with this tide, SW education is emphasized in terms of national policy in Korea. The Ministry of Education expanded the curriculum for SW subjects through the 2015 Revised Curriculum, requiring elementary schools to educate basic SW units for more than 17 hours and middle schools to educate for more than 34 hours [6]. Compared to the 2009 revised curriculum, the 2015 revised curriculum strengthened SW education along with basic training for hardware [7]. As a result of the analysis of the revised curriculum in 2015 shows, the difficulty of learning elements is exceedingly high compared to the content level of the course, and the problem of overlapped learning elements was raised [8]. Therefore, the curriculum to be revised in 2022 argues that the programming areas should be allocated the highest proportion due to the importance of processing information effectively in computer systems, algorithms, programming, data, and information society, and ethics areas [8]. In addition, it operated leading SW education schools for elementary, middle, and high schools with the aim of spreading SW education from 2014 to 2020, and has been supporting leading AI education schools since 2021. And the Ministry of Science and ICT is also carrying out an SW-centered university support project [9].

As shown above, SW-based changes in various industries, education, and social perceptions continue to increase. Consequently, computer programming skills are not limited to specific fields for those who do not major in computer-related ones, and it is difficult to show their industrial competitiveness without strengthening their capabilities for SW. However, students feel difficult for learning computer programming [10]-[12], and students' perceptions of programming education differ depending on their majors [13]. As the aim of programming language is communicating computers, using it less frequently will lead to deterioration inevitably.

Therefore, in this research, a survey after completing the basic programming course of non-majors is utilized for analyzing the intention to use the programming language, and examine whether there are actual differences depending on the majors. Through this, in order to further increase students' intention, this research aims to use it as basic data that can modify the current educational strategy and curriculum.

Section 2 investigates previous studies, Section III presents the methodology of the study, and Section IV verifies it with a statistical methodology. The last section summarizes the overall contents of this study and presents conclusions and future tasks. 


\section{LITERATURE REVIEW}

A decade from now, when current high school students will live as the main producer and central generation of society, the industry with SW will be centered on expanding the entire industrial structure and driving growth. The training of SW is necessary and important because the workforce with this flow will lead the society. The Ministry of Science and ICT has been working on supporting 'SW-centered university' since 2015. The main purpose of this project was to enhance industry and national competitiveness by innovating SW education by universities, and to achieve development in SW education through the medium of projects conducted by each university. In other words, the project pushes for a project that fundamentally revolutionizes university SW education. The first project started in 2015 and finished at the end of 2020, followed by the second stage. As a result, as the first phase of the project, the Ministry of Science and ICT selected 35 SW-centered universities across the country and provided 2 billion won per year to each school.

The SW-centered university project aims to carry out the task of training the technical personnel required by the industry to an appropriate level. Therefore, this project is designed to innovate universities' SW education based on field demand and operates as a national policy strategy to develop domestic SW industry engines [14]. Since the project aims to foster SW talent with problem-solving capabilities to lead the SW-centered society, it is necessary to secure the final success of the project and long-term stability in the system. From this point of view, it is important that universities across the country who participated in the SW-centered university project can produce curriculum that faithfully reflects the demands of SW capabilities needed by the industry. This involves a complete reorganization of the SW curriculum corresponding to existing computer science, and education on aspects of creative problem solving and cooperative thinking are necessarily included. In line with this curriculum reorganization, background knowledge at the level of major subjects in various fields is required, which will have the goal of fostering convergence talent that combines SW knowledge. Evaluation methods, reflux and improvement measures for teachers who are selected and trained for education are also important factors. In addition, the spread of SW value is essential from the perspective of business expansion, which provides additional policies and processes to promote cooperation to spread SW-centered university education. The educational characteristics of SW-centric universities are more focused on convergence education and industry-specific education than on traditional computer engineering curriculum. Therefore, the process of educating SW basic subjects reflecting the characteristics of each major department is included for SW non-majoring students. It also encourages the operation of SW convergence education courses for non-majored students and supports the establishment of convergence education in various aspects. It supports the development of a process to understand the situation of the site through direct exchange with the industry, such as SW consignment education, industry field trips, SW-related events, IT industry seminars, and expert invitation lectures. In addition, after building basic skills through open-source SW education, the company will operate education from an industry-oriented perspective beyond practical programs of various school education such as industry-academic cooperation R\&D and intern programs. As an educational goal, the project aims to strengthen students' problem-solving skills, logical thinking skills, creative thinking skills, and develop communication and collaboration skills through cooperative activities such as project performance. In such educational projects, an analysis of the efficiency and effectiveness of educational performance based on resource input is important. Therefore, it is necessary to redefine the evaluation concept considering the characteristics of academic achievement in terms of SW education. The definition of academic achievement is a comprehensive concept that covers all cognitive, descriptive, and physical functional areas according to their original purpose. In order to apply this concept to school situations, it is necessary to carry out this concept by considering the full components of academic achievement of individual school-educated students.

Academic achievement in this definition is descriptive based on the level of learning in the curriculum and needs to be calculated including the achievement of both physical areas. In this study, the concept of academic achievement is based on the usability and availability of a particular SW, so it is limited to the promotion of the degree of learning of curriculum knowledge in its original definition.

\section{Study ObJective And Methods}

In the section related to qualitative measurement of academic achievement in the preceding study, we identified it mainly as a measurement of general educational achievement and a study of the achievement of subjects specialized in the subject of study. In terms of achievement as a result of effort, a student's academic achievement is derived from the effectiveness of schooling and student participation. Achievement is a representative educational indicator that is evaluated through the results of these two items and is later used as a basis for the process of university selection. Achievement is understood to be the most important data for student evaluation in terms of objective data on outcomes for education. In addition, the achievement is closely related to the aspects of students' academic achievement and rediscovery of themselves, so the academic achievement is an important indicator for learners themselves, their families, and educators. SW education has a wide variety of factors that affect achievement in terms of education that is widely used in everyday life. Therefore, since the influence of factors and their processes are complicated, we analyze them separately which are performance expectations, effort expectations, and social influences. The factor traditionally presented in performance expectations is intelligence. Although intelligence has a disadvantage that is difficult to be quantified and accurately measured, the impact of the IQ on academic achievement is clearly higher than other factors including home and school. Objectifying the connection between academic performance and intelligence shows a large degree of influence as a single indicator. However, if a student is not suitable for a particular field, intelligence and 
achievement in that field show different results. This is because the indicators of aptitude are determined before students enter higher education and are not applied through a single education. Therefore, as making a high achievement for subjects in disparate areas from a student's aptitude is demanding, it is essential to exclude students who have negative interest in a particular area when analyzing the achievement. In the statistical analysis of our research, students who chose the course by themselves and had not taken the course before were chosen as statistical parameters, In terms of subject characteristics, SW education is based on an understanding of logical structure, and depending on the teaching method, it can be a mathematical subject or a subject that deals only with logical flow. For the analysis in this paper, Venkatesh et al' Unified Theory of Acceptance and Use of Technology (UTAUT) methodology is used. UTAUT is a model that improves explanatory power by integrating existing models, since the existing technology acceptance model cannot keep up with the speed of change in information systems [15]. Thus, achievement in this study focuses on how much attention can be received to the underlying theory of SW. In a similar perspective on the relevance of education, home background, economic and cultural environments may affect SW education, but in this paper, the factors are addressed only in terms of access to SW [16]. Secondly, in terms of effort, learning performance refers to the degree of learning, which is the ability to have until completing a particular curriculum achieved by the students. Indicators and evaluation criteria for effort have an incremental structure of mutual improvement. In order to have objective standards in this respect, an assessment of learning performance is carried out. Effort expectation refers to the student's patience and sincerity in the course of study in this respect to improve achievement. In particular, the expectation of effort has a significant association with the environment and can be controlled by learner individuals. Efforts have a direct effect on improving academic performance. Furthermore, as they are related to their usual learning attitude, they affect students' academic performance. Efforts and learning attitudes are highly interrelated, so they are continuously interconnected and affect academic performance in the process of change [17]. In this process, the expectation of effort will be applied to the assessment as the factor that most reflects the characteristics of the student. In evaluation, it is preceded by analyzing students' learning and achievement to establish appropriate performance criteria and evaluation criteria for learning performance. Feedback on each student's assessment criteria will then be conducted, and an analysis will be performed on whether these criteria can adequately evaluate the student's efforts. The results of this analysis are put together to finally supplement the evaluation tool, and the final evaluation tool is completed. According to the Learning Performance Assessment Method (KEC2005 / Korea Institute of Engineering and Education), the goal of learning is to reconsider the ability to apply mathematics, basic science, engineering knowledge and theory. Performance factors include mathematical knowledge applicability, basic scientific knowledge application, engineering knowledge and theoretical application. The aim was to apply mathematics, basic science, and engineering knowledge to solve engineering problems according to appropriate procedures. In this respect, improving performance-oriented achievement is important.

Thirdly, achievement goals based on social impact are the extent to which learners participate in the social role they want to achieve through learning. In this respect, the goal of achievement is to prove one's ability to learn to reach a social position [18]. In this process, students are primarily aimed at improving their abilities through mastery of learning content, and they have an expectation of efforts tailored to social impact to achieve it. Students conceptualize the social achievement goals they want to achieve, thereby creating a status of achievement. Students internalize this situation and control individual behavior to achieve their goals in the process. This trend shows that achievement goals may differ depending on the learners, even if each student in the same class is involved in the same course of study. Likewise, the analysis according to social impact also plays a major factor and is included in the analysis of this study.

\section{EXPERIMENT AND RESULT}

A survey was conducted on students from three departments who took creative computing in Week 15, the last week of the Creative Computing class, and 129 valid data were obtained. The survey items used a seven-point scale consisting of "not at all" to "very much so". The demographic characteristics of the respondents is shown in Table I. The majority of the students are freshman, and the proportion of sophomores or higher is around $5 \%$.

\begin{tabular}{|c|c|c|c|}
\hline \multicolumn{2}{|c|}{ Characteristics } & \multirow{2}{*}{$\begin{array}{l}\mathrm{N} \\
57\end{array}$} & \multirow{2}{*}{$\begin{array}{l}\% \text { of total sample } \\
44.19\end{array}$} \\
\hline Gender & Male & & \\
\hline & Female & 72 & 55.81 \\
\hline \multirow{4}{*}{ Grade } & Freshman & 122 & 94.57 \\
\hline & Sophomore & 3 & 2.33 \\
\hline & Junior & 1 & 0.78 \\
\hline & Senior & 3 & 2.33 \\
\hline \multirow[t]{3}{*}{ Department } & A & 37 & 28.68 \\
\hline & $\mathrm{B}$ & 54 & 41.86 \\
\hline & $\mathrm{C}$ & 38 & 29.46 \\
\hline
\end{tabular}

\section{KMO and Bartlett's Test}

\begin{tabular}{l|r|r}
\hline Kaiser-Meyer-Olkin Measure of Sampling Adequacy. & .812 \\
\hline $\begin{array}{l}\text { Bartlett's Test of } \\
\text { Sphericity }\end{array}$ & Approx. Chi-Square & 1193.052 \\
\cline { 2 - 3 } & df & 55 \\
\cline { 2 - 3 } & Sig. & .000 \\
\hline
\end{tabular}

Fig. 1. KMO and Bartlett's test.

First, factor analysis was performed using SPSS v26. As shown in Fig. 1, the Kaiser-Meyer-Olkin (KMO) value is 0.812 and Bartlett's sphericity test is statistically significant at 0.000 to analyze factors and reliability. The commonality of the variances explained by the extracted factors was greater than or equal to 0.5 , and the variances were determined to be quite explanatory by the extracted factors. Three factors with an eigenvalue of 1 or higher were extracted and showed $81.917 \%$ explanatory power. Fig. 2 shows that it is appropriate to extract three factors. As a result of factor 
rotation through the orthogonal rotation method Varimax, as shown in Fig. 3, the factor loading is greater than 0.4 and all variables within a factor are bundled significantly.

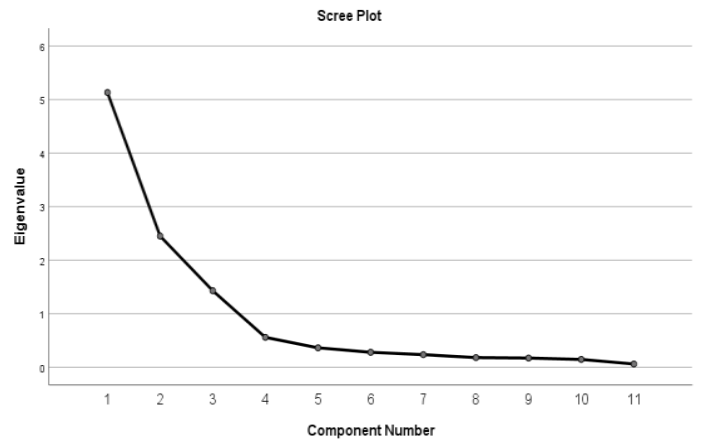

Fig. 2. Scree plot.

\begin{tabular}{|c|c|c|c|}
\hline \multicolumn{4}{|c|}{ Rotated Component Matrix ${ }^{a}$} \\
\hline & \multicolumn{3}{|c|}{ Component } \\
\hline & 1 & 2 & 3 \\
\hline EE1 & .924 & .086 & .091 \\
\hline EE3 & .910 & .136 & .091 \\
\hline EE4 & .873 & .029 & .139 \\
\hline EE2 & .854 & .199 & .174 \\
\hline PE4 & .030 & .885 & .212 \\
\hline PE3 & -.007 & .851 & .208 \\
\hline PE1 & .255 & .836 & .159 \\
\hline PE2 & .204 & .794 & .228 \\
\hline $\mathrm{S} 12$ & .128 & .254 & .921 \\
\hline SI1 & .099 & .234 & .918 \\
\hline SI3 & .213 & .223 & .816 \\
\hline \multicolumn{4}{|c|}{$\begin{array}{l}\text { Extraction Method: Principal Component } \\
\text { Analysis. } \\
\text { Rotation Method: Varimax with Kaiser } \\
\text { Normalization. }\end{array}$} \\
\hline
\end{tabular}

Fig. 3. Rotated component matrix.

Secondly, reliability analysis of input variables was performed. As shown in Table II, the values of Cronbach's alpha from performance expectations, effort expectations, and social impacts are above 0.6 and the factors are determined to consist of reliable variables.

\begin{tabular}{|l|l|l|}
\hline \multicolumn{1}{|c|}{ TABLE II: RELIABILITY TEST } \\
\hline & $\begin{array}{l}\text { Cronbach's } \\
\text { Alpha }\end{array}$ & $\begin{array}{l}\text { Cronbach's alpha based } \\
\text { on standardized items }\end{array}$ \\
\hline $\begin{array}{l}\text { Performance } \\
\text { expectancy }\end{array}$ & 0.895 & 0.897 \\
\hline Effort expectancy & 0.928 & 0.928 \\
\hline Social influence & 0.919 & 0.920 \\
\hline $\begin{array}{l}\text { Python Programming } \\
\text { Intention }\end{array}$ & 0.932 & 0.932 \\
\hline
\end{tabular}

Third, regression analysis was performed using the mean values of the variables. As a result of the correlation analysis, all factors are significant at 0.05 levels, performance expectations and social effects are highly correlated above 0.6 and effort expectations are relatively high. In Table III, the model-data fit and ANOVA table showed a $\mathrm{R}$ squared score of 0.607 , which implies regression model explanatory power of $60.7 \%$. Durbin-Watson determines that there is no autocorrelation at 1.943 , which is close to 2. In the ANOVA table, the statistic $F$ value was 64.451 , significantly at the significance level of 0.05 . VIFs of all factors, such as Table IV, were found to be less than 10 without problems of multicollinearity, significant at 0.05 levels and had a positive impact on Python programming intentions. The standardization factor for performance expectations is 0.43 , which is found to have the greatest impact on dependent variables and is found to exert influence in the order of social impact and effort expectations. Standardized residuals, Cook distances, and standardized DFFIT were reviewed to determine whether the values were outliers.

TABLE III: MODEL SUMMARY AND ANOVA

\begin{tabular}{|c|c|c|c|c|c|}
\hline Model & $\mathrm{R}$ & $\begin{array}{c}\mathrm{R} \\
\text { squar } \\
\mathrm{e}\end{array}$ & $\begin{array}{c}\text { Adjusted } \\
\text { R square }\end{array}$ & $\begin{array}{c}\text { Std. error } \\
\text { of the } \\
\text { estimate }\end{array}$ & Durbin-Watson \\
\hline 1 & 0.779 & 0.607 & 0.598 & 0.831 & 1.943 \\
\hline Model & $\begin{array}{c}\text { Sum of } \\
\text { squares }\end{array}$ & $\mathrm{df}$ & $\begin{array}{c}\text { Mean } \\
\text { square }\end{array}$ & $\mathrm{F}$ & Sig. \\
\hline Regression & 133.586 & 3 & 44.529 & 64.451 & 0.000 \\
\hline Residual & 86.362 & 125 & 0.691 & & \\
\hline Total & 219.948 & 128 & & & \\
\hline
\end{tabular}

\begin{tabular}{|c|c|c|c|c|c|c|}
\multicolumn{7}{c|}{ TABLE IV: COEFFICIENT } \\
\hline Model & $\begin{array}{c}\text { Unstandardized } \\
\text { coefficients }\end{array}$ & $\begin{array}{c}\text { Standardized } \\
\text { coefficients }\end{array}$ & $\mathrm{t}$ & Sig. & VIF \\
\cline { 2 - 7 } & $\mathrm{B}$ & $\begin{array}{c}\text { Std. } \\
\text { error }\end{array}$ & $\mathrm{B}$ & & & \\
\hline Constant & -0.176 & 0.375 & & -0.471 & 0.639 & \\
\hline $\begin{array}{c}\text { Performance } \\
\text { expectancy }\end{array}$ & 0.485 & 0.073 & 0.430 & 6.624 & 0.000 & 1.341 \\
\hline $\begin{array}{c}\text { Effort } \\
\text { expectancy }\end{array}$ & 0.186 & 0.058 & 0.193 & 3.232 & 0.002 & 1.137 \\
\hline $\begin{array}{c}\text { Social } \\
\text { influence }\end{array}$ & 0.330 & 0.058 & 0.372 & 5.664 & 0.000 & 1.372 \\
\hline
\end{tabular}

The standardized residuals range from -2.722 to 2.275 , less than the absolute value criterion of 3.0, Cook distance between 0.000 and 0.07 , and the standardized DFFIT from -0.087 to 0.118 with an absolute value criterion of less than 2.0 .

Based on the previous empirical analysis, additional analysis was performed with the aim of the utilization, which is essential to the operation of the lecture for the purpose of future improvement. Further analysis was made to improve the utilization of the lecture. Effort expectations were lowest as factors affecting dependent variables. Thus, it requires a strategic approach to students based on statistical evidence that Python programming is not easy for non-majored students. Therefore, it was investigated that intentions of Python programming differ depending on the department. An independent sample $\mathrm{T}$ test is performed in which sample means obtained from each population are extracted independently from each other and tested against each other. Table $\mathrm{V}$ is the basic statistics of Python programming intentions of students according to their major. Although there is no difference in average between the Department $A$ and the Department B, the Department $\mathrm{C}$ was found to be relatively low at 4.315. As shown in Table VI, Levene's equality of variance test shows that the variances of the two populations are the same, thus independent sample $\mathrm{T}$ tests are performed based on the assumption of equal variances. The only test statistic between the Department A and the Department B is statistically significant because the t value is 2.074 and the significance probability is 0.041 which is less than 0.05. In other words, the mean Python programming 
intentions between the Department A and the Department B were not the same. It is concluded that this may vary in intention depending on the department.

TABLE V: GROUP STATISTICS

\begin{tabular}{|c|c|c|c|}
\hline Department & Mean & Std. Deviation & Std. Error Mean \\
\hline A & 4.892 & 1.222 & 0.201 \\
\hline B & 4.315 & 1.356 & 0.185 \\
\hline C & 4.737 & 1.279 & 0.207 \\
\hline
\end{tabular}

TABLE VI: INDEPENDENT SAMPLE TEST

\begin{tabular}{|c|c|c|c|c|c|}
\hline \multirow{2}{*}{ Dept. - Dept. } & \multicolumn{2}{|c|}{$\begin{array}{c}\text { Levene's Test for } \\
\text { Equality of Variances }\end{array}$} & \multicolumn{3}{|c|}{$\begin{array}{c}\text { t-test for Equality } \\
\text { of Means }\end{array}$} \\
\cline { 2 - 6 } & $\mathrm{F}$ & Sig. & $\mathrm{t}$ & $\mathrm{df}$ & Sig. (2-tailed) \\
\hline A - B & 0.557 & 0.457 & 2.074 & 8 & 0.041 \\
& & & & 9 & \\
\hline A - C & 0.137 & 0.712 & 0.537 & 7 & 0.593 \\
& & & & 3 & \\
\hline B - C & 0.133 & 0.716 & -1.505 & 9 & 0.136 \\
& & & & 0 & \\
\hline
\end{tabular}

\section{CONCLUSiOnS}

In this study, the UTAUT model was used to statistically analyze the Python programming intention of non-major college students, and it was confirmed that performance expectancy, effort expectancy, and social influence all had a significant effect on Python programming intention. In addition, as a result of the T-test, it was confirmed that there were differences depending on the department. As a result, the findings of this study are as follows.

It was found that the intention to use programming languages differs depending on the department, even though the students got the same educational content, assignments, and the same type of midterm and final exam questions under the same subject name. It was figured out that when looking at the average score of academic achievement by department, department B was the lowest at 66.3. D. Park and S. Choi (2009) analyzed the factors influencing elementary school students' math achievement, and an important factor for high-scorer students was chosen as the instructor's teaching method, and for that reason, low-scorer students judged that teacher explanation was somewhat difficult [19]. The low academic achievement of Department B is judged that some students who have completed the class show a high interest in programming, but most of them think that programming is not related to their major and future jobs. For instance, after the end of the class, in a lecture evaluation on instructors, some students expressed wonder, which was 'Is the subject really necessary as a liberal arts student?'. On the other hand, the average score of academic achievement in the remaining two departments shows little difference, which is 78.5 and 80.9 , respectively. Since these two departments are organized into basic subjects, such as statistics, which is centered on mathematics, and economics, they are likely to conduct data analysis in the future, and they will naturally have high interest and intention to use programming. In order to increase students' Python programming intention and academic achievement, it is necessary to establish a customized educational strategy tailored to the characteristics of the department.

In addition, performance expectancy and social influence were high, while effort expectancy were low. This result can be associated with the results of two phenomena. First, since performance expectancy are related to the development of students' vocational competencies, indexes are high in the field of SW education. Social impact is related to the transfer of an interest in education. If many students in the same department are interested in SW development, this indicator will increase. Effort expectancy is an indicator of ease in relation to using SW. Python has an aspect that makes it easier for non-majors to learn the basics than other programming languages. In this respect, the expectation of effort was confirmed to be a statistically significant value, and it shows that it is a common idea among students that it is actually easy to use. However, with regard to the low index showing the user's external perception, it is necessary to conduct an advanced analysis using structural equations in subsequent studies. In addition, depending on the case where professional characteristics are commonly associated with achievement and performance expectancy of each department, the introduction of additional methodologies for student competency indicators can be considered in further researches.

\section{CONFLICT OF INTEREST}

The authors declare no conflict of interest.

\section{AUTHOR CONTRIBUTIONS}

M. Cheon, O. Lee, and C. Mun developed the idea of research. H. Ha prepared the theoretical base of research and conducted a survey and statistical analysis of data.

\section{ACKNOWLEDGMENT}

This work was supported by the research fund of Hanyang Cyber University.

\section{REFERENCES}

[1] KOFAC. Introduction to SW centered society. [Online]. Available: https://www.software.kr/home/kor/contents.do?menuPos $=155$

[2] S. Choi, "Opportunities for higher education of artificial intelligence in Korea," International Journal of Engineering Research and Technology, vol. 13, no. 11, pp. 3428-3430, 2020.

[3] E. Jee. (2019). Digital transformation and software labor shortage. SPRI. [Online]. Available: https://spri.kr/posts/view/22846? code=industry_trend

[4] Y. Son, H. Ko, H. Han, and D. Rhee, "A study on a domestic SW technical manpower classification and growth strategy," The Journal of Korean Institute of Communications and Information Sciences, vol. 31, issue 3B, pp. 239-253, Mar. 2006.

[5] M. Kwon and S. Park, "Examination of the determinants of SW manpower' turnover intention: Testing the mediating role of job satisfaction," Journal of Information Technology Service, vol. 9, issue 1, pp. 73-90, Mar 2010.

[6] Ministry of Education. (2016). 2015 revised curriculum guide. [Online]. Available:

https://www.moe.go.kr/boardCnts/view.do?boardID=316\&lev=0\&stat us YN=C\&s $=$ moe \&m $=0302 \&$ opType $=\mathrm{N} \&$ boardSeq $=62381$

[7] B. Yu, J. Kim, and W. Lee, "Implication for construction computing system unit of the 2015 revised curriculum," The Journal of Korean Association of Computer Education, vol. 19, issue 2, pp. 31-40, Mar. 2016.

[8] J. Kim et al., "Proposing the informatics standard curriculum scheduled to be revised in 2022," The Journal of Korean Association of Computer Education, vol. 23, issue 1, pp. 1-28, Jan. 2020.

[9] Software-centered University, What is Software-centered University? [Online]. Available: https://www. swuniv.kr/33 
[10] J. Kim and E. Sohn, "Difficulty analysis of an introductory computer programming course for non-major students," Journal of Creative Information Culture, vol. 7, no. 2, pp. 69-77, May 2021.

[11] M. Konecki, "Problems in programming education and means of their improvement," DAAAM International Scientific Book 2014, 2014, ch. 37, pp. 459-470.

[12] Y. Bosse and M. A. Gerosa, "Why is programming so difficult to learn? Patterns of difficulties related to programming learning mid-stage," ACM SIGSOFT Software Engineering Notes, vol. 41, issue 6, pp. 1-6, Jan. 2017.

[13] W. Kim, "Exploring the direction of granular basic-software education considering the major of college students," Journal of The Korean Association of Information Education, vol. 23, issue 4, pp. 329-341, Aug. 2019.

[14] Software policy research institute. (2021). Monthly software-oriented society. [Online]. Available: https://spri.kr/posts/view/23241?code=magazine

[15] V. Venkatesh, M. G. Morris, G. B. Davis, and F. D. Davis, "User acceptance of information technology: Toward a unified view," MIS Quarterly, vol. 27, no. 3, pp. 425-478, Sep. 2003.

[16] R. E. Ferdig, "Examining social software in teacher education," Journal of Technology and Teacher Education, vol. 15, no. 1, pp. 5-10, Jan. 2007.

[17] J. S. Coleman, Equality and Achievement in Education, Routledge, 2019.

[18] G. Ladson-Billings, "From the achievement gap to the education debt: Understanding achievement in US schools," Educational Researcher, vol. 35, issue 7, pp. 3-12, Oct. 2006.

[19] D. Park, and S. Choi, "Research on analysis of factors affecting mathematics academic achievements: A case study of an elementary school in Busan," Communications of Mathematical Education, vol. 23 , issue 2, pp. 383-398, May 2009.

Copyright $\odot 2022$ by the authors. This is an open access article distributed under the Creative Commons Attribution License which permits unrestricted use, distribution, and reproduction in any medium, provided the original work is properly cited (CC BY 4.0).

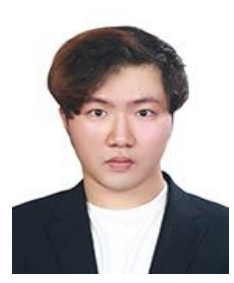

MinJong Cheon earned his BS degree from Hanyang University, Seoul, Korea in 2020. Now he is a PhD student and works as a researcher of information systems lab at Hanyang University in Seoul, Korea. His major of interest and expertise are information systems, deep learning, and machine learning.

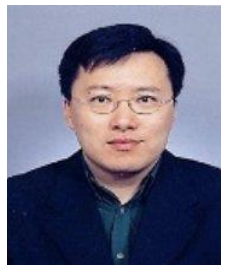

Ook Lee earned his $\mathrm{PhD}$ degree from Claremont Graduate University, USA in 1997. Now he serves as a professor of information systems at Hanyang University in Seoul, Korea. His major of interest and expertise are information systems, deep learning, and machine learning.

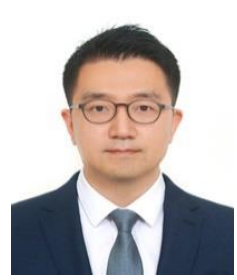

Changbae Mun earned his $\mathrm{PhD}$ degree from Hanyang University, Seoul, Korea in 2018. Now he serves as a professor of information system and communication engineering in Hanyang Cyber University in Seoul, Korea. His major of interest and expertise are intelligent platform, information systems, and data analytics.

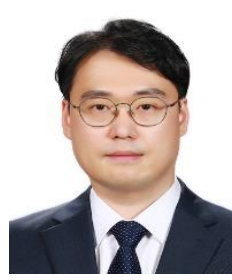

Hyodong Ha earned his $\mathrm{PhD}$ degree from Hanyang University, Seoul, Korea in 2020. Now he serves as a collaboration professor of software education committee, office of academic affairs in Hanyang University in Seoul, Korea. His major of interest and expertise are big data, information systems, and software education. 